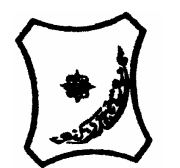

Bayero Journal of Pure and Applied Sciences, 1(1):16 - 19

Received: September, 2008

Accepted: November, 2008

\title{
PREDICTED PEAK EXPIRATORY FLOW IN HUMAN AND THE CLINICAL IMPLICATION OF DIFFERENCES ACROSS RELATED FORMULAE: A PROPOSED GUIDELINE STANDARD REFERENCE FOR ASTHMA
}

\author{
${ }^{1 *}$ Salisu, A. I., ${ }^{2}$ A.B. Adelaiye, ${ }^{3}$ and M. Babashani \\ ${ }^{1}$ Department of Human Physiology, Faculty of Medicine, Bayero University, Kano \\ ${ }^{2}$ Department of Human Physiology, Faculty of Medicine, Ahmadu Bello University, Zaria. \\ ${ }^{3}$ Department of Internal Medicine, Aminu Kano Teaching Hospital, Kano \\ *Correspondence Author
}

\begin{abstract}
In an attempt to examine the differences between Peak Expiratory Flow (PEF) formulae in the literature so as to assess the potential impact of those differences on the interpretation of clinical guidelines for asthma management, the present study was carried out. We calculated $100 \%$ PEF values using formula developed by (Gregg, 1973) at $\mathbf{5 0 ^ { \text { th } }}$ percentile for age, height and weight obtained from our study (Salisu et al., 2007) and classified the percent predicted PEF in to severity groups according to national asthma guidelines (NAEPP, 1991 and 1997). Choosing different formulae could give an individual in the age range of 15-19 years a 100\% predicted PEF as low as $402 \mathrm{~L} / \mathrm{min}$ and as high as $412 \mathrm{~L} / \mathrm{min}$; and another woman in the age range of 30-34years a classification of severe (47\%) using one, but moderate (71\%) using another. This indicates that predicted PEF varied widely across formulae and choice of a particular formula may alter guidelinebase care. This work has therefore accepted a recently published population-base equation proposed as the reference standard for future asthma guidelines.
\end{abstract}

Keywords: Peak expiratory flow, Asthma, Practice guidelines, reference values

\section{INTRODUCTION}

The National Asthma Education and Prevention Program (NAEPP) Expert Panel Report (NAEPP, 1991 and 1997) recommend use of the Peak Expiratory Flow (PEF) in the assessment and disposition of the asthmatic patients in the emergency department. The algorithm presented in the 1997 guidelines classified asthma exacerbation as: severe (PEF $<50 \%$ of predicted value), moderate (PEF 50\%-79\% predicted), and mild (PEF $80 \%$ or greater of predicted). Initial therapy and subsequent disposition are often decided by the resulting classification of asthma severity. An improvement to $70 \%$ is considered a good response to acute asthma treatment (NAEPP, 1991 and 1997).

The 1997 NAEPP guidelines also encourage use of a personal best PEF as an alternative to formula-derived predicted PEF. The guidelines state that the personal best PEF may be estimated after a 2-to-3-week period in which the patient records PEF 2 to 4 times per day. The personal best is usually achieved in the early afternoon measurement after maximal therapy has stabilized the patient.

There are many different formulae for PEF. The 1991 Expert Panel Report used 2 reference standards for adults (Gregg, 1973 and Leiner et al., 1963). These studies were performed on relatively small groups of normal subjects in England. Both of these reference equations were derived more than 25 years ago from measurements taken by a Wright Peak Flow Meter, except for one group, which derived equations from measurements taken by a vitalometer and a Wright Peak Flow Meter (Leiner et al., 1963).

During the past 25 years, there has been increasing recognition that, in addition to age, sex, weight and height differences in PEF, there are lung function differences between subjects from different races. For example, it has been reported that black males have spirometric parameters that are $10-13 \%$ lower than whites males of European descent (Lu souef, 1997). This is assumed to be due to decreased thoracic to leg length ratio compared to Europeans. It is understandable that a formula that provides reasonably accurate predictions for Europeans may overestimate the severity of an asthma exacerbation in blacks and vice versa. Thus, formulae derived from Europeans appear not to be generalizable to black Africans. Use of the older studies should consider this limitation.

Thus, our specific aim was to review reference equations that have been derived from populations in Europe and different localities in Nigeria, considering the heterogeneous populations that we treat in our accident and emergencies, so as to assess how use of a specific formula might affect guidelines- based care.

\section{MATERIALS AND METHODS}

In addition to the reference equations from the NAEPP, an internet search for PEF prediction equations in Nigeria was made. 
Studies that included asymptomatic, lifelong nonsmoking subjects were reviewed, sample size not considered. Some of the formulae from the NAEPP were calculated as liters per second, we therefore multiplied these by 60 to make all of the formulae comparable.

We used the $50^{\text {th }}$ percentile for height, weight and age from our study (Salisu et al., 2007) and applied the reference formulae to these "average" parameters on one of the 1991 recommended (NAEPP) Expert panel Report prediction PEF equations (Gregg,1973). This was used because it is obtained ten years after that of (Leiner et al., 1963), it also included the race on which the study was carried out, has more female participants and their prediction equation has differed slightly from what is obtainable in Africa. By applying the NAEPP algorithm (1997) cut points of $50 \%$ and $80 \%$ predicted PEF to formula (Salisu et al., 2007) based on the parameters from our subjects, outcome of whether the change in predicted PEF could lead to a change in guideline classification of acute asthma severity or not was evaluated.

The data was analyzed using simple percentages, range, mean and standard error of estimate as appropriate using Minitab statistical software package. Microsoft Word and Excel 8.0 Windows (Microsoft Corp, Redmond, WA) were used for the tabulations. The corresponding predicted PEFs are shown for subjects that have been classified as $50 \%$ and $80 \%$ predicted PEF by NAEPP (1997) guidelines. The level of significance is set at $P<0.05$.

\section{RESULTS}

Table 1 describes the demographic characteristics of subjects and the formulae from each of the selected studies. The wide range of $100 \%$ predicted PEF is presented in Table2 and is most dramatically shown in the 20-24 year age range, in whom $100 \%$ PEF could be anywhere from 379 to 426 liters per minute (mean and standard error of the men $404 \pm 0.98$ liters per minute).

Tables 3 and 4 demonstrated the variability of predicted PEF when the various formulae are applied to the $50 \%$ and $80 \%$ PEF, respectively, based on NAEPP guidelines. There is variability in the absolute values since the formulae used in table 1 represents a composite of different investigations, carried out in different parts of the world and by different investigators. For example, a woman in the age range of 30-34years of average height and weight, who presented with a 50\%, predicted PEF according to (Gregg, 1973); would have (Knudson et al., 1976; Nku etal., 2006 and Salisu, etal., 2007), predicting a PEF of $49 \%, 47 \%$ and $49 \%$ respectively a "severe" exacerbation, while (Njoku, 1999) would predict a PEF of $71 \%$ - a "moderate" exacerbation.

Table 1: Predicted Peak Expiratory Flow Rate Equations and Demographic Data from Studies by many researchers

\begin{tabular}{|c|c|c|c|c|}
\hline Investigator & $\begin{array}{l}\text { Year of publication/ } \\
\text { Location / Device Used }\end{array}$ & Subjects & Race & Formula \\
\hline \multirow[t]{3}{*}{ Leiner et al. } & 1963 & $n=155$ & - & $\mathrm{F}$ \\
\hline & New Jersey, USA & $15-69$ years & & $\operatorname{PEF}(\mathrm{L} / \mathrm{min})=[2.93-(0.0072 \mathrm{~A}) \mathrm{H}]$ \\
\hline & Vitalometer + WPFM & $\mathrm{F}=(30 \%)$ & & \\
\hline \multirow[t]{3}{*}{ Gregg and Nunn } & an 1973 & $\mathrm{n}=401$ & W $100 \%$ & $\mathrm{~F}$ \\
\hline & London, UK & $(F=34 \%)$ & & $\operatorname{PEF}(\mathrm{L} / \mathrm{min})=198.07+3.07-0.0477 \mathrm{~A}^{2}+1.42 \mathrm{H}$ \\
\hline & WPFM & 14-64years & & \\
\hline \multirow[t]{5}{*}{ Knudson et al. } & 1976 & $n=746$ & & $\mathrm{~F}($ Age $<20 y)$ \\
\hline & Tucson, AZ, USA & $\mathrm{F}=(61 \%)$ & W $100 \%$ & $\operatorname{PEF}(\mathrm{L} / \mathrm{min})=60[-3.916+0.157 \mathrm{~A}+0.049 \mathrm{H}]$ \\
\hline & Pneumotachygraph & $9-80$ years & & \\
\hline & & & & $\mathrm{F}($ Age $>20 y)$ \\
\hline & & & & $\operatorname{PEF}(\mathrm{L} / \mathrm{min})=60[-0.735-0.025 \mathrm{~A}+0.049 \mathrm{H}]$ \\
\hline \multirow[t]{3}{*}{ Njoku and Anah } & 1999 & 1009 & B $100 \%$ & $\mathrm{~F}$ \\
\hline & Port Harcourt, Nigeria & $\mathrm{F}=(33.8 \%)$ & & $\operatorname{PEF}(\mathrm{L} / \mathrm{min})=2.40 \mathrm{Age}+3.04 \mathrm{HT}-14.28$ \\
\hline & WPFM & $15-82$ years & & \\
\hline \multirow[t]{2}{*}{ Nku et al. } & 2006 & 600 & & $\mathrm{~F}$ \\
\hline & $\begin{array}{l}\text { Calabar, Nigeria } \\
\text { WPFM }\end{array}$ & 18- 57years & $\begin{array}{l}\text { PEF }(L / r \\
\text { B } 100 \%\end{array}$ & in $)=-38.80+(210.83 H)+(1.650 A)+(0.252 W)$ \\
\hline \multirow[t]{2}{*}{ Salisu et al. } & 2007 & $n=250$ & & $\mathrm{~F}$ \\
\hline & $\begin{array}{l}\text { Kano, Nigeria } \\
\text { WPFM }\end{array}$ & $15-54$ years & B $100 \%$ & $\operatorname{PEF}(\mathrm{L} / \mathrm{min})=0.5 \mathrm{~A}+0.15 \mathrm{~W}+350.37$ \\
\hline
\end{tabular}


Table 2: Variability of $\mathbf{1 0 0 \%}$ Peak Expiratory Flow Rate Among the different age groups

\begin{tabular}{lcc}
\hline Age range & $\begin{array}{l}\text { Females } \\
\text { Mean } \pm \text { SEM }\end{array}$ & Range \\
\hline $15: 19$ & $401 \pm 6.27$ & $402-412$ \\
$20: 24$ & $404 \pm 0.98$ & $379-426$ \\
$25: 29$ & $393 \pm 1.55$ & $372-411$ \\
$30: 34$ & $382 \pm 1.33$ & $358-397$ \\
$35: 39$ & $368 \pm 2.11$ & $359-377$ \\
$40: 44$ & $346 \pm 1.78$ & $338-355$ \\
$45: 49$ & $318 \pm 4.21$ & $310-325$ \\
\hline
\end{tabular}

Table 3: Predicted Percent Peak Expiratory Flow Rate of various Formulae Based on 50\% Peak Expiratory Flow Rate Predicted by some widely used Adult Formulae

\begin{tabular}{|c|c|c|c|c|c|c|c|}
\hline Investigators & 5:19yr & $20: 24 y r$ & 25:29 yr & $\begin{array}{l}\text { Females } \\
30: 34 \text { yr }\end{array}$ & 35:39 yr & $40: 44$ yr & $45: 49$ yr \\
\hline Leiner & 54 & 54 & 55 & 56 & 58 & 55 & 62 \\
\hline Knudson & 48 & 48 & 48 & 49 & 51 & 51 & 51 \\
\hline Njoku & 64 & 64 & 67 & 71 & 75 & 80 & 80 \\
\hline Nku & 41 & 42 & 45 & 47 & 50 & 54 & 58 \\
\hline Salisu & 46 & 46 & 47 & 49 & 51 & 55 & 60 \\
\hline
\end{tabular}

Table 4: Predicted Percent Peak Expiratory Flow Rate of various Formulae Based on $80 \%$ Peak Expiratory Flow Rate Predicted by some widely used Adult Formulae

\begin{tabular}{|c|c|c|c|c|c|c|c|}
\hline \multirow[b]{2}{*}{$\begin{array}{l}\text { Investigators } \\
\text { yr }\end{array}$} & \multicolumn{6}{|c|}{ Females } & \multirow[b]{2}{*}{$45: 49$} \\
\hline & $15: 19 y r$ & $20: 24$ yr & $25: 29 \mathrm{yr}$ & $30: 34$ yr & $35: 39$ yr & $40: 44 \mathrm{yr}$ & \\
\hline Leiner & 84 & 86 & 88 & 90 & 93 & 87 & 99 \\
\hline Knudson & 77 & 77 & 78 & 79 & 81 & 82 & 84 \\
\hline Njoku & 102 & 102 & 107 & 113 & 121 & 128 & 140 \\
\hline $\mathrm{Nku}$ & 66 & 67 & 67 & 75 & 81 & 85 & 92 \\
\hline Salisu & 73 & 73 & 75 & 78 & 82 & 88 & 96 \\
\hline
\end{tabular}

\section{DISCUSSION}

The choice of reference formulae for PEF has implications for those who conduct asthma research, those who design asthma practice guidelines, and primary and emergency care clinicians, who must make treatment and disposition decisions for the individual patient.

First, the issue of asthma research is affected when investigators attempt to compare studies and outcomes of asthma care based on different reference formulae. Referring again to Table 3 and 4, 100\% PEF results in widely different absolute values, depending upon which formula is used. Unless we are told that two studies are comparing percent predicted PEF based on the same formula, then we must use caution in interpreting the results.

For hospitals in Nigeria, the lack of a single reference formula compounded by the lack of interchangeability of formulae, present a problem. The decision will go to that reference formula most familiar or easy to use especially those with available tables or nomograms. Across Nigerian hospitals, utilization of different formulae may show wide variability in outcomes, as the severity classification will not be truly comparable. For example, an institution that uses formula (Njoku,1999) which estimates a relatively high $100 \%$ PEF would place patients in to a more severe category than the institution that uses (Nku et al., 2006) or (Salisu et al., 2007) formulae who predicted a relatively low $100 \%$ PEF values. This could lead to a scenario in which one Emergency Department (ED) experiences a higher relapse rate than another ED despite using the same PEF cutoff point of $70 \%$.

Presently, in Nigeria, we lack a single reference PEF equation that can be used across the country due to the fact that; earlier reference values estimated the mean population PEFs without producing prediction equations, the recent prediction equations are sectional in origin and lack heterogeneous spread to accommodate the diverse nature of a Nigerian state. For practicing Clinicians, the variability and complexity of the PEF reference equations need not to be a concern, because, the resulting formulae can be translated in to a simple table and nomogram. This can make them easy to use especially in busy clinical setting. However, in Nigeria at present cautious has to be exercised when using a particular predicting PEF equation before a physician makes a decision on a patient. 
For example, a female Nigerian in the age range of 35 to 39 years, using (Gregg, 1973) equation would produce a cutoff value of 299 for $80 \%, 262$ for $70 \%$ and 187 for $50 \%$ predicted PEF, but 444 for $80 \%, 388$ for $70 \%$ and 277 for $50 \%$ when using prediction equation (Nku, 2006). Equally, using equation (Salisu, etal. 2008) will give 296 for $80 \%, 259$ for $70 \%$ and 185 for $50 \%$. Even though there seems to be a close agreement between equations (Nku et al., 2006 and Salisu et al., 2007), there is a significant difference $\mathrm{p}<0.05$ in the mean predicted PEF values. The choice of formula to select as a standard should satisfy several criteria. First, the population studied should be representative of the patient's seen in the ED in terms of age, sex, and race and tribe/ethnicity. This increases the generalizability of the formula. Second, the number of subject should be large so that the estimate of the predicted PEF includes wide range of variations. The confidence interval of an estimate is determined by the standard deviation of the measurement divided by the square root of the sample size. Consequently, the larger the number of subjects tested, the more the confidence we can have in the estimated PEF predicted by the formula. Third, the more recently the measurements have been taken, the more likely that it will be that the equipment used in the investigation will be

\section{REFERENCES}

Gregg, I. Nunn, A.J., (1973): Peak Expiratory flow in normal subjects. Br Med J. 3 282-284

Knudson, R.J. Slatin, R.C., Lebowitz M.D., (1976): The maximal expiratory flow-volume curve: Normal standards, variability and effect of age. Am Rev Respir Dis. 113: 587-600

Leirner, G.C., Abramowitz, S. Small, M., (1963): Peak Expiratory flow rate: standard values for normal subjects; use as a clinical test of ventilator function. Am Rev Respir Dis; 88: 644-651

Lu Souef, P.N., (1997): Paediatric prediction equations for PEF (growth, ageing, gender, race and health). Eur Respir J; 10 Suppl 24: 75s-79s

National Asthma Education Program Expert Panel Report II (1997): Guidelines for the diagnosis and management of Asthma. Bethesda, MD: National Institute of Health Publication no. 97-4051 representative of the equipment in current practice. This allows investigators an easier opportunity to reproduce the results. It is worth noting that none of these three indigenous prediction equations satisfy these criteria, hence we lack common language in the objective assessment of asthma exacerbation as well as a solid foundation on which to evaluate and strengthen current clinical guidelines. Since our aim is the standardization of predicted PEF for each guideline decision mode, lack of exact agreement between the predicted equations should be a challenge to the young scientist in Nigeria. Therefore, if one equation led to a given age group's predicted PEF being systemically higher or lower then future guidelines should adjust their cutoff, predicted PEFs to reconcile their recommendations to the instrument available in clinical practice. The 1997 NAEPP guidelines encourage the use of a "personal best" PEF as an alternative to formula-derived predicted PEF, but due to financial reason and low literacy level of our people, personal PEF readings are not usually been observed. In addition, not all the Physicians attending to asthma cases encourage patients to record PEF changes at home for comparison with clinical readings. Therefore, the use of a personal best PEF is still a mirage in Nigeria.

National Asthma Education Program Expert Panel Report (1991): Guidelines for the diagnosis and management of Asthma. Bethesda, MD: National Institutes of Health Publication no. 91-3642

Njoku, CH. Anah, C O. (1999): A new formular for predicting Peak Expiratory Flow Rate in Adult Nigerians. Sahel Med. J. 2: 39-44.

Nku, C.O, Peters E.J, Eshiet A.I, Bisong, S.A, Osim E.E. (2006): Prediction formulae for lung function parameters in females of south eastern Nigeria. Nig. J. of Physiol. sci. 21: 43-47.

Salisu, A.I, Adelaiye, A.B, and Babashani, M. (2007): A formula for predicting peak expiratory flow rate in non-pregnant and pregnant women at second and third trimesters of pregnancy in kura local government area, kano, Nigeria. Medwell Res. J. Med. Sci. 5: 279- 283. 